\title{
GEOSPATIAL ASSESSMENT OF VULNERABILITIES OF CROPLANDS TO FLOODING RISKS: A CASE STUDY OF PHILIPPINE RIVER BASINS
}

\author{
D. M. G. dela Torre ${ }^{1,2, *}$, P. K. A. dela Cruz ${ }^{1}$, R. P. Jose ${ }^{1}$, N. B. Gatdula ${ }^{1}$, A. C. Blanco ${ }^{3}$
}

\begin{abstract}
${ }^{1}$ Phil-LiDAR 2 Program, University of the Philippines-Training Center for Applied Geodesy and Photogrammetry (UP-TCAGP), Department of Geodetic Engineering, College of Engineering, University of the Philippines Diliman - (delatorredm, pka.delacruz, ronalynpjose, nerigatdula)@gmail.com

${ }^{2}$ School of Environment, University of Auckland, Auckland, Private Bag 92019, New Zealand - d.delatorre@auckland.ac.nz

${ }^{3}$ Department of Geodetic Engineering, College of Engineering, University of the Philippines Diliman - acblanco@up.edu.ph
\end{abstract}

KEY WORDS: Vulnerability Assessment, Flood Hazard, Analytic Hierarchical Process, Agriculture, River Basin

\begin{abstract}
:
This study utilized the Analytic Hierarchical Process and spatial analysis using various datasets to produce sub-provincial vulnerability maps with $20 \mathrm{~km}$ resolution. Five (5) indicators for exposure, four (4) for sensitivity and seven (7) for adaptive capacity were selected and weighted using aggregated rankings from twenty-three (23) experts. Based on these indicators, gridded maps of exposure, sensitivity, adaptive capacity, and vulnerability were produced. Using river basins as the unit of analysis, the Pampanga River Basin was determined to be the most vulnerable, followed by the Agus River Basin, having the highest sensitivity, and Buayan River Basin, having the lowest adaptive capacity. These areas have large agricultural regions and river systems with high flooding risk. Coastal regions in southern Mindanao and eastern Visayas were also highly vulnerable to flooding. High poverty rates with high dependence on agricultural incomes and low adaptive capacities characterize these areas. Vulnerability hotspots can easily be identified through these maps, which have value in planning initiative to reduce potential damages of floods to agricultural areas.
\end{abstract}

\section{INTRODUCTION}

Disastrous flooding events have been increasing in the recent years with damaging consequences to resources and human life. The Asian region registered majority of flood occurrences in the world at $40 \%$ in the last quarter of the 20 th century (Dutta \& Herath, 2004). In the same period, nearly $50 \%$ of flood-related mortalities occurred in the region (Doocy et al., 2013). The Philippines is among the top ten countries in Asia affected by flooding due to annual monsoonal rains and numerous typhoons. Its geographical location also makes it susceptible to El Niño and La Niña climate effects that can range from dry weather conditions to extreme rainfall episodes (Lasco et al., 2012; Toda et al., 2016). Recent climate projections on precipitation show that wet periods will get wetter while drier periods become drier. Typhoon frequency shows no significant trends but strong typhoons $(>150 \mathrm{~km} / \mathrm{h})$ have been associated with El Niño episodes (PAGASA, 2011).

The agricultural sector is placed at a highly vulnerable position under the effects of climate change as large areas in the country are devoted to agricultural uses and the livelihood of a significant proportion, 11.29 million people or $29 \%$ of the total workforce as of 2016 , is dependent on agriculture. $32 \%$ of the total land area of the Philippines is devoted to permanent and temporary crops such as rice, corn, coconut, and banana (Philippine Statistics Authority, 2016). Approximately 20 typhoons enter the Philippine Area of Responsibility with 9 making landfall (Cinco et al., 2016). Typhoon-related damages and monsoonal rains have contributed to the highest damages to agriculture. Typhoon Yolanda caused more than P28 billion damages in agriculture in 2013. In 2014, more than P21 billion in damages to coconut areas was dealt by Typhoon Glenda. Rice production worth P9 billion was lost due to Typhoons Karen and Lawin in 2016 (DA, 2017). Flood damages are unavoidable but by identifying which areas are susceptible to severe effects of this hazard due to underlying biophysical and socioeconomic factors, mitigating measures can be adopted by agricultural planners and farm managers.
How society responds to perturbation is determined by its vulnerability, literally meaning its capacity to be hurt or wounded (Kates, 1985). It involves a combination of factors that determine the degree to which someone's life, livelihood, property and other assets are in risk by an event or cascade of events in nature (Wisner et al., 2003). Vulnerability can hereby be a function of sensitivity of the system to changes in climate, exposure of the system to climatic hazards, and its adaptive capacity to aforementioned changes. A vulnerability assessment in the environmental, social and ecological contexts is imperative as these are all encompassed by climate change (Bogardi et al., 2005).

Recent studies have focused on mapping vulnerabilities as a planning tool apart from conducting basic research. Assessments can be utilized in all disaster management phases but are particularly useful for preparedness, prevention, and mitigation. Information derived from these is a vital step in contingency planning (Sehgal \& Dhakar, 2016). In the Philippine setting, with the passage of the Climate Change Act of 2009 (Republic Act [RA] 9729), local government units have taken steps to include assessments into their development and land use plans. Vulnerability assessments (VA) is an important component of local climate change action plans and integrates physical and social aspects of vulnerability. These assessments are designed specifically for municipal-level studies. However, it is increasingly important to expand the scope of VAs to cover larger landscapes with sufficient spatial resolution. Efforts have been made to produce national-level risk maps and to use quantitative methods to produce vulnerability indices (Manila Observatory, 2005; Ballesteros, 2012). In smaller administrative levels, geographic information systems (GIS) and remote sensing (RS) has been useful to provide a method to integrate various spatial information. This approach was used to assess agricultural vulnerabilities to typhoon and in varying scales such as in the barangay (sub-municipality administrative unit) and households (Mallari, 2016; Mendoza et al., 2014). However, these initial studies have been sparse either in coverage or in detail. This study aims to fill this knowledge gap and assess the nationwide 
vulnerability of agricultural lands in the Philippines to flood hazards with moderate spatial resolution and incorporating various datasets measuring biophysical attributes and socioeconomic characteristics of the country.

\section{MATERIALS AND METHODS}

\subsection{Study Area}

An archipelago comprised of more than 7,000 islands, the Philippines is located in the South East Asian region, bounded by the West Philippine Sea/South China Sea on the west and Philippine Sea on the east. Lying just above the equator, the Philippines' warm waters power the formation of typhoons (Price, 2013). It is one of the most disaster-prone countries in the world, belonging to a region informally called the 'Pacific Ring of Fire' (SEPO, 2013). According to the state weather bureau, Philippine Atmospheric, Geophysical and Astronomical Services Administration (PAGASA), an average of 20 tropical cyclones hit the Philippines each year. In 2013 alone, a total of 25 storms entered the country including Typhoon Haiyan (Yolanda), counted among the most destructive typhoons in recent history. A mostly agricultural country, the Philippines has 9.671 million hectares of agricultural land (CAF, 2002) contributing to $10 \%$ of the country's GDP (PSA, 2014) and agricultural employment totalling in 11.80 million persons which is about $31 \%$ of the country's total employment (PSA, 2014).

Process and flows in a river system, such as those associated with important agricultural areas, can go beyond administrative boundaries. Hence, further analysis has been scaled to the major river basins in the country. DENR's River Basin Control Office defines major river basins as those with drainage areas over 1,400 $\mathrm{m}^{2}$. The country has 421 principal river basin of which 18 are designated as major river basins. The largest of these is the Cagayan River Basin which has an area of $27,753 \mathrm{~km}^{2}$ while the second is the Mindanao River Basin, also the largest in the island of Mindanao, at 23,169 $\mathrm{km}^{2}$. The Pampanga River Basin, the $4^{\text {th }}$ largest, is commonly referred to as the Philippine rice bowl since it contains major rice-producing areas, specifically in the provinces of Nueva Ecjia and Pampanga. Also, Metropolitan Manila, the largest urban agglomeration in the country, is located in the Pasig-Laguna de Bay River Basin. By having specific analyses in a river basin context will provide valuable inputs in the Integrated River Basin Management approach being utilized by public agencies (DENR-RBCO, 2007; Jaranilla-Sanchez et al., 2011; Almaden, 2015; Salmivaara, 2015).

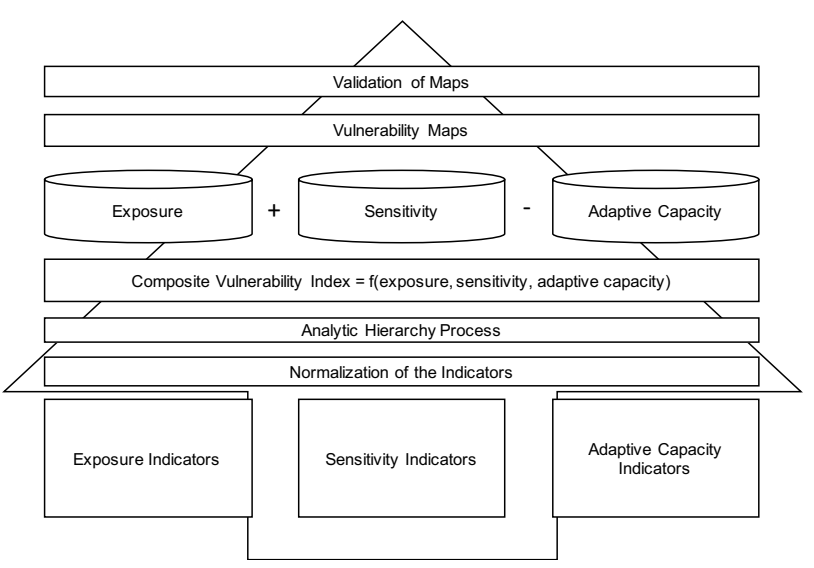

Figure 1. Methodological framework for vulnerability assessment employed in this study.

\subsection{Composite Vulnerability Index}

The methodology (see Figure 1) is largely based on the threecomponent concept of vulnerability as a function of a system's exposure, sensitivity and adaptive capacity to climate hazards (Turner et al., 2003). A list of indicators was formulated during a focused group discussion (FGD) with nationwide experts and provincial government officials, specifically from the fields of agriculture, development and disaster risk management. They were tasked with selecting among a pre-determined list of indicators and assessing its merits and inclusion to each component. The indicators for exposure were mostly geophysical in nature, as it is defined to be the degree to which a system is exposed to a climatic variation. This study focused on indicators relevant to riverine floods that occurs over a specific river basin (RB), as determined by Jose and colleagues (2017). The Intergovernmental Panel on Climate Change (IPCC, as cited by Mallari, 2016), defines sensitivity as an internal factor which may also be the current state of the system, and is the degree to which a system is affected by exposure to climate change. While for adaptive capacity, it is the ability of a system to adjust to climate variability to moderate potential damages, take advantage of opportunities and cope with consequences. Sensitivity and adaptive capacity indicators characterize mainly socioeconomic features of the provinces. In the design of the composite vulnerability index, high numerical values of exposure and sensitivity contribute to increasing the vulnerability of an area while adaptive capacity has a reverse contribution, meaning high values can decreases the vulnerability index of the region.

\subsection{Indicator Selection and Analytic Hierarchical Process}

Indicator-based vulnerability assessments for flood are the most common and also the most widely-used method, preferred by policy makers due to its ability to relate different types of information into a single metric (Nasiri, Yusof, \& Ali, 2016). However, it is subject to a high degree of variability due to the list of indicators being subject to the researchers' opinions. The FGD, as conducted in this study, allowed external experts to debate and discuss the merits of the indicators for inclusion in each of the three components, reducing inherent biases from the researchers. In the conduct of the FGD, the experts mainly removed irrelevant and redundant indicators. The indicators in sensitivity and adaptive capacity had the greatest amount of debate as some were moved from one component to another, such as in the case of income from sensitivity which was pre-grouped in adaptive capacity. Also, experts discussed whether the characteristics being measured by the indicator had positive or negative effects in relation to the component it belonged to. The final list of indicators for this study included five (5) for exposure, four (4) for sensitivity and seven (7) for adaptive capacity, for a total of sixteen (16) indicators.

The composite vulnerability index is made up of sub-indices of each component. The method to compute for these indices are dependent on the weights assigned to each indicator. Numerous studies have employed arbitrary assignment of weights based on expert judgement or by employing equal weights (Becarri, 2016). Utilizing multi-criteria decision making (MCDM) methods as a participatory method enables decision makers and stakeholders to provide their inputs on the assessment based on their needs and understanding of the problem (Ouma \& Tateishi, 2014). This study uses the Analytic Hierarchical Process (AHP) developed by Saaty (1980). This is a multi-criteria decision method that utilizes pairwise comparisons of the relative importance of indicators to the component. The rigorous computational method 
Table 1. List of indicators used in the study and the data sources.

\begin{tabular}{|c|c|c|}
\hline Component & Indicator & Data Source \\
\hline \multirow[t]{5}{*}{ Exposure } & $\begin{array}{l}\text { Percentage of irrigation to total } \\
\text { cropland area }\end{array}$ & DA-BSWM \\
\hline & Flood Hazard (Level) & DREAM \\
\hline & Flow Depth & DREAM \\
\hline & Flood Hazard (Area) & DREAM \\
\hline & Land Use/Cover Map & NAMRIA \\
\hline \multirow[t]{4}{*}{ Sensitivity } & Hunger Incidence & PSA \\
\hline & Income from agriculture & DA-BAS \\
\hline & Population Density & PSA \\
\hline & Poverty Rate & PSA \\
\hline \multirow[t]{7}{*}{$\begin{array}{l}\text { Adaptive } \\
\text { Capacity }\end{array}$} & $\begin{array}{l}\text { Access to alternative water sources } \\
\text { (domestic and agricultural usage) }\end{array}$ & NAMRIA \\
\hline & $\begin{array}{l}\text { Access to financial aid (government } \\
\text { and non-government support - } 4 \mathrm{Ps} \text { ) }\end{array}$ & DSWD \\
\hline & Access to Rehabilitation and Aid & DA-BAS \\
\hline & $\begin{array}{l}\text { Agriculture products are covered by } \\
\text { insurance }\end{array}$ & DA-BAS \\
\hline & Disaster and hazard funding & DBM \\
\hline & Household assets/savings & DA-BAS \\
\hline & Income for Non-Agricultural Sources & DA-BAS \\
\hline
\end{tabular}

Acronyms: DA-BSWM - Department of Agriculture-Bureau of Soils and Wate Management, DA-BAS - Department of Agriculture - Bureau of Agricultural Statistics, DBM - Department of Budget Management, DREAM - Disaster Risk Exposure and Assessment for Mitigation/Phil-LiDAR 1, NAMRIA - National Mapping and Resource Information Authority, DSWD - Department of Social Welfare and Development, PSA Philippine Statistics Authority

also allows for the evaluation of each respondent's consistency in answering the survey forms.

This study utilized the consistency ratio to determine which expert's ratings were to be included. A tolerance value of $20 \%$ was used in computing this. When each expert's ratings were not within tolerable limits, the survey was re-administered until their ratings were within the consistency ratio. All twenty-three (23) experts were eventually able to provide ratings within the allowable range.

Table 1 shows the indicators that were selected and its accompanying data sources. The provincial boundary dataset shapefile was sourced from the Philippine Statistics Authority (PSA). Exposure indicators were in spatial data formats. For percent irrigation to total land area, the percentage of areas classified as irrigated was obtained from the Land Use System Map of Department of Agriculture - Bureau of Soils and Water Management (DA-BSWM). The flood hazard and flow depth were processed by the University of the Philippines - Training Center for Applied Geodesy and Photogrammetry (UP-TCAGP) and is available for most major RBs and flood plains in the Philippines (UP-TCAGP, 2015). The 2010 land use and land cover (LULC) map from the National Mapping and Resource Information Authority (NAMRIA) had multiple classes but was processed to only contain annual crops and perennial crops classes.

Sensitivity and adaptive capacity datasets were primarily in tabular format with provincial data as the coarsest spatial unit.
Hunger incidence was obtained from the PSA, specifically from its 2011 Annual Poverty Survey. Income from agriculture was acquired from the Integrated Farm Household Survey (IFHS) of 2003 from Department of Agriculture - Bureau of Agricultural Statistics (DA-BAS). Population density was from the 2015 National Census using the PSA shapefile for area statistics. Poverty rate was from PSA through the 2015 Full Year Poverty Statistics. Access to alternative water resources was calculated as the percentage of water bodies within a province. The proxy for access to financial aid was from the Department of Social Welfare and Development's Pantawid Pamilyang Pilipino Program (DSWD-4Ps) calculated as the percentage of beneficiaries from the total provincial population. Insurance data, household assets and savings, income from non-agricultural sources was from IFHS. Disaster and hazard funding was calculated as $5 \%$ of each provincial and municipal government's Annual Investment Plan.

In order for the datasets to be directly comparable, all indicator values were normalized to have values ranging only from zero (0) to one (1). The following linear normalization formula was used for the datasets:

$$
Z_{i, j}=\frac{X_{i, j}-X_{i}^{\min }}{X_{i}^{\max }-X_{i}^{\min }}
$$

where, $Z_{i j}$ is the normalized value of indicator $i$ to area of interest $j, X_{i j}$ is the original value of indicator $i$ to area of interest $j, X_{i}^{\max }$ is the highest value, and $X_{i}^{\min }$ is lowest value.

Each indicator will then have be aggregated into a single index per vulnerability component. This is done using a weighted-sum method. Equation (2),

$$
A=\sum_{i=1}^{n} w_{i} x_{i}
$$

where $A$ is the computed index for each vulnerability component with $n$ indicators, $w_{i}$ is the weight assigned to indicator $i$ and $x_{i}$ is the normalized value of the indicator $i$.

Interviews and surveys were designed and delivered to twentythree (23) experts from the academe, government sector, public development institutions and civic society organizations. This yielded weights $\left(w_{i}\right)$ for each indicator. Lastly, the weights were aggregated using arithmetic mean.

\subsection{Spatial Analysis}

All layers were imported into ArcGIS ArcMap for geoprocessing. A $20 \mathrm{~km} \mathrm{X} 20 \mathrm{~km}$ grid was generated to provide greater detail for analysis at the sub-provincial level. The gridded approach was adopted as there may be transboundary process that can be lost if the unit of analysis was at the barangay or municipality level. Also, since datasets are of different scales and scope, the grid serves to harmonize the spatial unit of analysis. The layers for each of the components and the final vulnerability map was generated to hold the datasets representing each indicator in Table 1. Normalized values were computed using the Field Calculator Tool of ArcMap for each province. The layers were then intersected with the grid and administrative boundaries and joined into the component layers. The resulting weighted sum values per component were also computed with the Field Calculator. Finally, the composite vulnerability index was also computed, using Equation 3.

Vulnerability $=($ Exposure + Sensitivity $)-$ Adaptive Capacity (3) 
For map symbology and value breaks, the geometric mean was selected. This method ensures that each class range has the same number of values, derived from minimizing the square sum of elements in each class (Liu el al., 2013). Resulting maps were compared to damage assessment reports from the Department of Agriculture [DA]. The reports are hazard-specific for each province and data from 2008 to the 2013 was used. Total pesovalue damages to different agricultural and non-agricultural resources were utilized for the comparison. Analyses were limited to the 18 major RBs in the country and, in addition, the Eastern Visayas region for a cursory examination of vulnerabilities of Typhoon Haiyan-affected areas.

\section{RESULTS AND DISCUSSIONS}

\subsection{Weights from AHP}

The final weights for each indicator per component are presented in Table 2. The sum of all the weights added up to 1.00. For exposure, $70.98 \%$ of the total weights belonged to indicators describing flood hazards, specifically flood hazard levels, flow depth and area affected by flood hazards. This information was the result of high-resolution hazard mapping from airborne LiDAR surveys and flood modelling from the DREAM Project. The assessed hazard levels were deemed by the experts as the most important indicator to describe the exposure of an area. In contrast, experts cited that the land use/cover and presence of irrigation infrastructure is of less significance to describe exposure. These two indicators also have notable socio-economic considerations as compared to the geophysical nature of flood hazard, indicating that for the experts, exposure is characterized more by natural and physical features of an area.

In sensitivity, the four indicators have been judged almost equally. Income from agriculture was determined as the highest with a weight of 0.2730 , then hunger incidence at 0.2553 , followed by population density at 0.2402 , and lastly by poverty rate at 0.2315 . Since sensitivity is described as to the degree a certain indicator or resource will be affected by the environmental shock, agricultural incomes was ranked highly due to the potential economic losses of crop damages from flooding events. Also, food security, as described by hunger incidence, can be affected greatly by damaged food stocks and a higher populations per unit area also indicates high sensitivity to floods. Poverty rate was included as a proxy for vulnerable sectors of the municipality.

For the indicators of adaptive capacity, access to alternative water sources has the highest weight, indicating the importance of having available water sources for both irrigation and domestic use in coping to flooding disasters. Funding for disaster and hazard-related activities and access to rehabilitation and aid (in the form of financial and development projects) are the next two most important indicators, stressing the vital role of resources of both within and outside the municipality to support adaptation programs. The last three are indicative of household capacity to manage domestic resource in coping to effects of disasters. These are the presence of insurance for crops, availability of household savings, and financial gain from non-agricultural livelihoods.
Table 2. Weights of each indicator derived from the results of AHP.

\begin{tabular}{|c|c|c|}
\hline Component & Indicator & $\begin{array}{l}\text { Weight } \\
\text { Allocation }\end{array}$ \\
\hline \multirow[t]{5}{*}{ Exposure } & $\begin{array}{l}\text { Percentage of irrigation to total } \\
\text { cropland area }\end{array}$ & 0.1328 \\
\hline & Flood Hazard (Level) & 0.2737 \\
\hline & Flow Depth & 0.2185 \\
\hline & Flood Hazard (Area) & 0.2176 \\
\hline & Land Use/Cover Map & 0.1574 \\
\hline \multirow[t]{4}{*}{ Sensitivity } & Hunger Incidence & 0.2553 \\
\hline & Income from agriculture & 0.2730 \\
\hline & Population Density & 0.2402 \\
\hline & Poverty Rate & 0.2315 \\
\hline \multirow[t]{7}{*}{$\begin{array}{l}\text { Adaptive } \\
\text { Capacity }\end{array}$} & $\begin{array}{l}\text { Access to alternative water } \\
\text { sources for domestic and } \\
\text { agricultural usage }\end{array}$ & 0.1773 \\
\hline & Access to financial aid & 0.1201 \\
\hline & $\begin{array}{l}\text { Access to Rehabilitation and } \\
\text { Aid }\end{array}$ & 0.1628 \\
\hline & $\begin{array}{l}\text { Agriculture products are } \\
\text { covered by insurance }\end{array}$ & 0.1449 \\
\hline & Disaster and hazard funding & 0.1643 \\
\hline & Household assets/savings & 0.1231 \\
\hline & $\begin{array}{l}\text { Income for Non-Agricultural } \\
\text { Sources }\end{array}$ & 0.1074 \\
\hline
\end{tabular}

\subsection{Flood Vulnerability of Major River Basins}

The flood exposure maps (Fig. 2a) showed that the highest flood exposure occurred in important RBs and coastal regions. Figure 4 also delineated the 18 major RBs, a water management unit with an area greater than $1000 \mathrm{~km}^{2}$, made up of smaller units of watersheds (Cruz, 1999; DENR-RBCO, 2016). Areas with high exposure levels were also primarily agricultural land that are lowlying or have extensive river systems, such as in the Pampanga $\mathrm{RB}$ in Luzon. Lower exposure levels were found within boundaries of RBs, which are mostly elevated, mountainous regions and with minimal agricultural land cover.

For the flood sensitivity map (Fig. 2b), highest levels were found in the provinces of Sultan Kudarat, Maguindanao, (North) Cotabato, South Cotabato, and Sarangani, all located in the southern portion of Mindanao. The areas, all in Region XII and Autonomous Region of Muslim Mindanao, have a collective population of 5,719,209. These provinces have a large percentage of their economic income from agricultural activities, indicating an exacerbating effect on the provinces' sensitivity due to reliance on agriculture. Large damages to their croplands will have a negative effect on its population's livelihoods.

The adaptive capacity map (Fig. 2c) showed distinct spatial patterns. The majority of Luzon have medium to high coping capabilities as these areas have more urban areas and high development. Areas with moderately low to low resiliencies were concentrated to eastern Philippines. These regions are highly exposed to typhoons as well with three of the five most destructive typhoons since 2009 namely typhoons Haiyan, Bopha, and Rammasun directly affecting these areas. Also low adaptive capacity was found in the Sulu Archipelago, Northern Panay Island and Northern Mindanao. Many of these areas are primarily agricultural and less developed, in contrast to its counterparts in Luzon. 

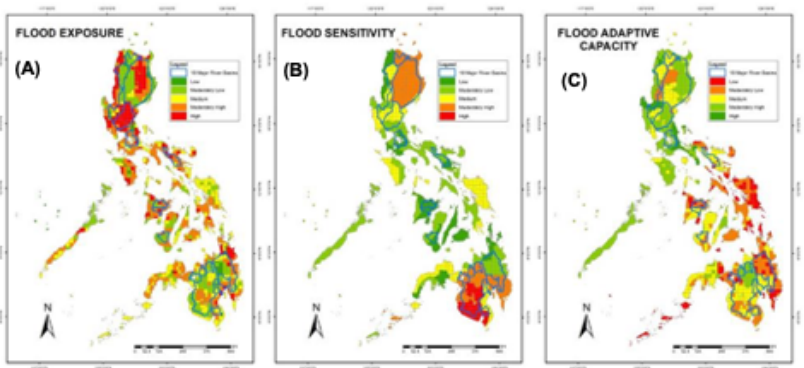

Figure 2. Nationwide maps of exposure, sensitivity and adaptive capacity with the locations of the 18 major river basins (RBs).

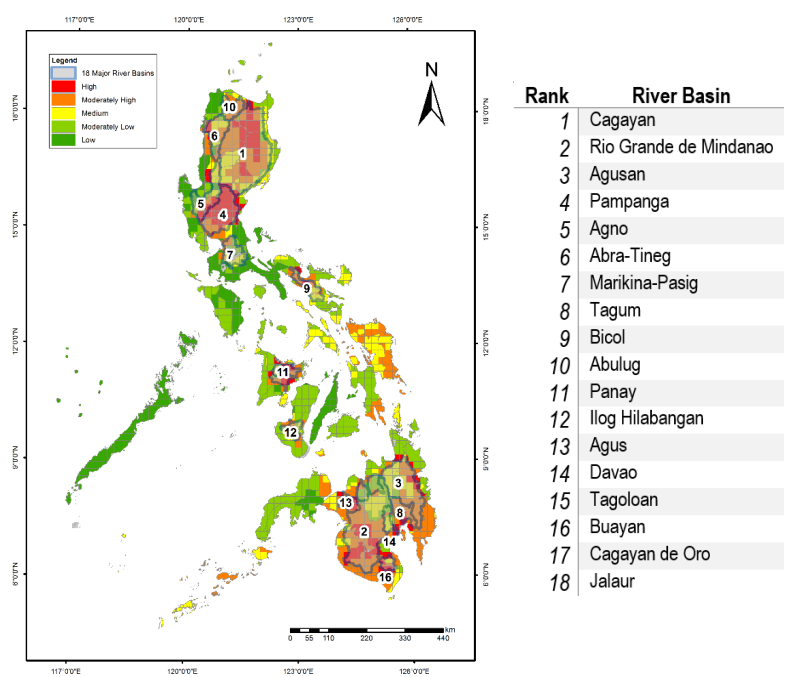

Figure 3. Flood vulnerability map for the Philippines with the locations of the 18 major RBs. Not labelled on the map are Cagayan de Oro Basin (\#17) located in between Agus and Agusan basins and Jalaur Basin (\#18) below the Panay Basin.
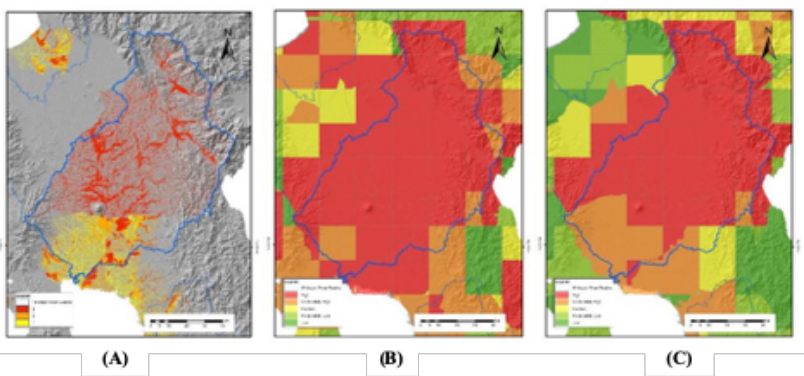

Figure 4. Pampanga RB maps of (A) flood hazard from the DREAM Project, (B) flood exposure, and (C) flood vulnerability. The flood hazard map is derived from modeled 5-year return period scenarios and classified as 1 - low hazard, 2 - moderate hazard, and 3 - high hazard.

The composite vulnerability map in Figure 3 showed the spatial patterns. High vulnerabilities were associated with RBs, as in the case of the Pampanga and Cagayan RBs in Luzon, Panay River Basin in Panay Island, and Rio Grande de Mindanao RB in Mindanao. However, there are also other areas that have medium to moderately high vulnerability levels. These are in the Eastern Visayas region, islands in the Sulu Archipelago, and coastal regions in southern Mindanao. These areas have significant agricultural land devoted to rice, corn, and vegetables-
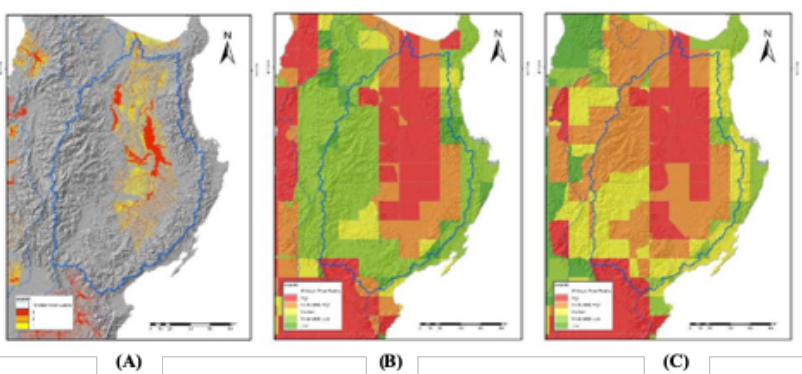

Figure 5. Cagayan Valley RB maps of (A) flood hazard from DREAM Project, (B) flood exposure, and (C) flood vulnerability. The flood hazard map is derived from modeled 5-year return period scenarios and classified as 1 - low hazard, 2 - moderate hazard, and 3 - high hazard.
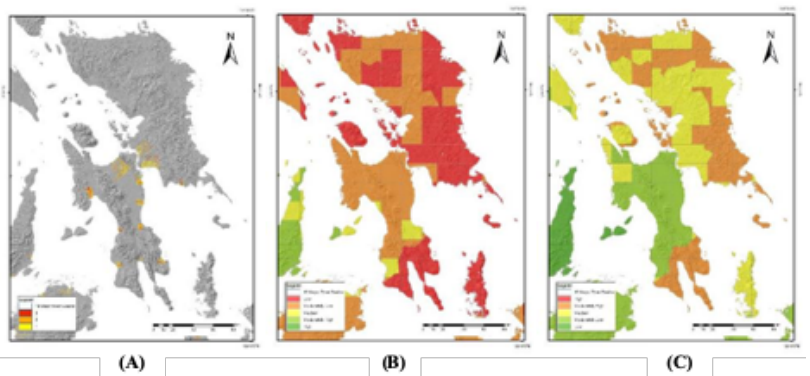

Figure 6. Maps of the Eastern Visayas Region of (A) flood hazard from Phil-LiDAR Program, (B) flood adaptive capacity, and $(\mathrm{C})$ flood vulnerability. The flood hazard map is derived from modeled 5-year return period scenarios and classified as $1-$ low hazard, 2 - moderate hazard, and 3 - high hazard.

temporary crops that are vulnerable to damages from flooding (PSA, 2013). Highly urbanized areas such as Metropolitan Manila, Cebu, Rizal and Zamboanga have the lowest vulnerability scores.

By taking spatial averages of levels of vulnerabilities by RB, the most vulnerable RBs may be ranked and trends on the interplay between the three component indices can be noticed, specifically that high values of exposure and sensitivity contribute to higher vulnerabilities and conversely, high adaptive capacities decrease vulnerabilities. Table 3 shows the results of each RB. The five most vulnerable basins are Pampanga, Agus, Buayan, Cagayan and Tagum. In the case of Pampanga and Cagayan, both have moderately high adaptive capacity but this was offset by high exposure for Pampanga and high sensitivity for Cagayan. The Buayan RB has a high level of sensitivity which when combined with only medium exposure and medium adaptive capacity still makes it highly vulnerable to flooding. The Agus RB has the lowest adaptive capacity values of all basins and its vulnerability score was exacerbated by high sensitivity values.

Spatial averages provide a good overview the general location of hotspots. Going into greater detail, however, supplied more specific information on the geographical extent of flooding effects. The most vulnerable basin, the Pampanga RB, was shown to have high flood hazard over majority of its land area (Fig. 4a). This is due to the extensive spread of the river system and its tributaries in the area and the generally low, flat terrain. This contributed to higher exposure values (Fig. 4b) and consequently, high vulnerability over most of its area (Fig. 4c). Less vulnerable was its southern portion which is mostly made up of aquaculture ponds and urban centers. 


\begin{tabular}{lcccc}
\hline Basin Name & Mean Exposure & Mean Sensitivity & $\begin{array}{c}\text { Mean Adaptive } \\
\text { Capacity }\end{array}$ & $\begin{array}{c}\text { Mean } \\
\text { Vulnerability }\end{array}$ \\
\hline Pampanga & 0.3781 & 0.2343 & 0.3474 & 0.2650 \\
Agus & 0.0894 & 0.3123 & 0.1910 & 0.2108 \\
Buayan & 0.1187 & 0.3417 & 0.2527 & 0.2077 \\
Cagayan & 0.1662 & 0.2854 & 0.2925 & 0.1592 \\
Tagum & 0.1148 & 0.2852 & 0.2512 & 0.1488 \\
Rio Grande de Mindanao & 0.0916 & 0.3268 & 0.2725 & 0.1458 \\
Jalaur & 0.2056 & 0.1720 & 0.2420 & 0.1356 \\
Agusan & 0.1036 & 0.2253 & 0.2049 & 0.1240 \\
Panay & 0.1527 & 0.1639 & 0.1979 & 0.1187 \\
Davao & 0.0914 & 0.3018 & 0.2803 & 0.1129 \\
Bicol & 0.1750 & 0.1845 & 0.2627 & 0.0968 \\
Abra-Tineg & 0.1222 & 0.2472 & 0.2808 & 0.0886 \\
Abulug & 0.0896 & 0.2772 & 0.2870 & 0.0798 \\
Cagayan de Oro & 0.1078 & 0.2764 & 0.3075 & 0.0767 \\
Tagoloan & 0.1219 & 0.2620 & 0.3257 & 0.0582 \\
Agno & 0.1709 & 0.2277 & 0.3472 & 0.0515 \\
Ilog Hilabangan & 0.1186 & 0.1827 & 0.2649 & 0.0363 \\
Marikina-Pasig & 0.1481 & 0.1896 & 0.3764 & -0.0387 \\
\hline
\end{tabular}

Table 3. The 18 major river basins in the Philippines ranked on the basis of their spatially averaged indices for exposure, sensitivity, adaptive capacity and vulnerability of their agricultural land. The graduated color, from red to green, indicates increasing position of rank.

The Cagayan RB is the largest river basin in the country with an area of $25,469 \mathrm{~km}^{2}$. The scope of flooding hotspots in the river is also extensive. Similarly with the Pampanga RB, high flood hazard areas are concentrated near the river systems and riverbanks (Fig. 5a) in the Cagayan Valley. This resulted into the concentration of medium to high exposure values at the same vicinity of areas with flood hazards. Noticeably, the basin's outskirts have lower exposure values, as these contain less cropland due to its elevated and sloping terrain. This contributed to a lower vulnerability average for the basin.

The Eastern Visayas Region, also known as Region VIII, has no major river basins (Fig. 6a) but sizable areas have moderately high to high vulnerabilities (Fig. 6c). This can be attributed to the low adaptive capacity of these areas as shown in Figure 8b. Region VIII has one of the highest regionwide rates of poverty at $30.7 \%$ and one of its provinces, Northern Samar, being the third poorest at $47.9 \%$ in 2015 (PSA, 2016). During Typhoon Haiyan (local name: Yolanda) the area experienced high casualties, of 5,877 of the 6,300 killed, and high damages to crops and agricultural infrastructure valued at P 20.488 billion (NDRRMC, 2013; PSA, 2016; PSA, 2017).

\section{CONCLUSIONS AND RECOMMENDATIONS}

Using an indicator-based approach and participatory weighting methods to map and assess vulnerabilities of the agricultural sector, major river basins and coastal areas around the country has been determined as hotspots of flooding hazards. By using river basins and their boundaries as the unit of analysis, the spatial extent and severity of these vulnerabilities and contributing components of exposure, sensitivity, and adaptive capacity can be further understood. The Pampanga RB, a major crop-producing and population center was determined to be the most vulnerable, owing to its extensive river system and high hazard rating. Although some areas also have high values of adaptive capacity, these may be offset due to the compounding values of the other two exacerbating components. By being able to map out which areas are lacking in initiatives to increase coping capabilities, planning for climate change adaptation can be redirected and prioritized in these areas.

This approach provided a holistic method to assess vulnerability to flooding, incorporating various datasets to integrate climatic, natural and socio-economic factors to characterize vulnerabilities. And by utilizing geospatial tools and technology, this type of vulnerability assessment provides a geographically specific and highly reproducible means to asses, over a large spatial extent, where climate risks are significant. However, significant limitations to this approach exist. First is the availability of datasets that were used as inputs. Ideally, these should have similar spatial resolutions and acquired at the same time. Second, there is a degree of subjectivity involved in the weight determination. With enough experts, bias can be minimized and acceptable weights may be derived. Third, it is suggested that a sensitivity analysis be performed for the datasets to quantify uncertainties associated with data quality and their influence on the final values of the indices. Fourth, there are various formulas to quantify vulnerability thus it is worth exploring and comparing the results from the standard formula used in this study. As greater emphasis is being placed on science-based planning methods, the use of approaches similar to what was employed in this study will be beneficial for policymakers and regional planners in adapting and preparing for further flooding events. 


\section{ACKNOWLEDGMENTS}

The researchers would like to thank the Department of Science and Technology (DOST) for their financial support in this study. Department of Science and Technology- (DOST-PCIEERD for tirelessly monitoring progress and accomplishments, and University of the Philippines Diliman, Department of Geodetic Engineering - Training Center for Geodesy and Photogrammetry (UP DGE-TCAGP) for developing and implementing the methodologies for this study under Phil-LiDAR 2: Nationwide Detailed Resources Assessment Using LiDAR.

\section{REFERENCES}

Almaden, C. R. C., 2015. Management regimes of river basin organizations. Environmental Policy and Law, 45(3-4).

Ballesteros, M. M., 2012, September. Assessment of vulnerability to natural hazards at subnational level: provincial estimates for the Philippines. PIDS Policy Notes 2012-14, 1-6.

Beccari, B., 2016, March 14. A comparative analysis of disaster risk, vulnerability and resilience composite indicators. PLOS Current Disasters, $1 . \quad$ doi: 10.1371/currents.dis.453df025e34b682e9737f95070f9b970

Chakraborty, A., \& Joshi, P. K., 2016. Mapping disaster vulnerability in India using analytical hierarchy process. Geomatics, Natural Hazards and Risk, 7(1), 308-325. doi: 10.1080/19475705.2014.897656

Cinco, T. A., de Guzman, R. G., Ortiz, A. M. D., Delfino, R. J. P., Lasco, R. D., Hilario, F. D., ... Ares, E. D., 2016. Observed trends and impacts of tropical cyclones in the Philippines. International Journal of Climatology, 36(14), 4638-4650. http://doi.org/10.1002/joc.4659

Cruz, R. V. O., 1999. Integrated land use planning and sustainable watershed management. Journal of Philippine Development 47, 26(1), 27-49.

Department of Agriculture [DA]., 2017. Damages to agriculture sector. Quezon City, PH: Department of Agriculture - Field Programs Operational Planning Division.

Department of Environment and Natural Resources - River Basin Control Office [DENR-RBCO]., 2016. 18 Major River Basins in the Philippines. Retrieved from http://rbco.denr.gov.ph/MPDISPLAY/masterplans/HAN DBOOK/

Doocy, S., Daniels, A., Murray, S., \& Kirsch, T.D., 2013. The human impact of floods: a historical review of events 19802009 and systematic literature review. PLOS Currents Disasters, 1.

doi: 10.1371/currents.dis.f4deb457904936b07c09daa98ee8171a

Dutta, D., \& Herath, S., 2004. Trends of floods in Asia and flood risk management with integrated river basin approach. In Proceedings of the $2^{\text {nd }}$ International Conference of AsiaPacific Hydrology and Water Resources Association, Singapore, Vol. 1, 55-63.

Earth Observation Research Center, Japan Aerospace Exploration Agency [EORC-JAXA]. AMSR/AMSRE/AMSR2/TRMM Tropical Cyclone Database (Ver. 1.2). Retrieved http://sharaku.eorc.jaxa.jp/TYP DB/guide_e.html

Israel, D. C., \& Briones, R. M., 2012. Impacts of natural disasters on agriculture, food security, and natural resources and environment in the Philippines. Discussion Paper Series No. 2012-36. Makati, PH: Philippine Institute for Development Studies.

Jaranilla-Sanchez, P. A., L. Wang, \& Koike, T., 2011. Modeling the hydrologic responses of the Pampanga River basin,
Philippines: A quantitative approach for identifying droughts. Water Resour. Res., 47, W03514, doi:10.1029/2010WR009702.

Lasco, R., Delfino, R. J., Ragasa, M., \& Pulhin, F. B., 2012. The role of local government units in mainstreaming climate change adaptation: The case of Albay, Philippines. In: Local Climate Change and Society [Salih, M. A. M. (ed.)]. Routledge, London, UK and New York, NY, USA, 45-73.

Mallari, A. E. C., 2016. Climate Change Vulnerability Assessment in the Agriculture Sector: Typhoon Santi Experience. Procedia - Social and Behavioral Sciences, 216(October 2015), 440-451. http://doi.org/10.1016/j.sbspro.2015.12.058

Manila Observatory [MO]., 2005. Mapping Philippine Vulnerability to Environmental Disasters. Retrieved from $\mathrm{http} / / / \mathrm{vm}$. observatory.ph

Mendoza, M. E. T., The, B. D., Naret, H., Ballaran, V. G. J., \& Arias, J. K. B., 2014. Assessing vulnerability to climate change impacts in Cambodia, the Philippines and Vietnam: An analysis at the commune and household level. Journal of Environmental Science and Management 17(2), 78-91.

Nasiri, H., Yusof, M. J. M., \& Ali, T. A. M., 2016. An overview of flood vulnerability assessment methods. Sustainable Water Resources Management, 2, 331-336. doi: 10.1007/s40899-016-0051-x

National Disaster Risk Reduction and Management Council [NDRRMC]., 2013. Final report re effects of Typhoon "Yolanda" (Haiyan). Retrieved from http://ndrrmc.gov.ph/attachments/article/1329/FINAL_R EPORT re Effects of Typhoon_YOLANDA_(HAIYA N)_06-09NOV2013.pdf

Ouma, Y. O., \& Tateishi, R., 2014. Urban flood vulnerability and risk mapping using Integrated multi-parametric AHP and GIS: methodological overview and case study assessment. Water, 6, 1515-1545. http://doi.org/10.3390/w6061515

PEP-Asia Community-Based Monitoring System., 2012. Climate Change Vulnerability Mapping in the Philippines: A Pilot Study. Manila, PH: PEP-Asia CBMS Network Office.

Philippine Atmospheric, Geophysical and Astronomical Services Administration [PAGASA]., 2011. Climate change in the Philippines. $85 \mathrm{pp}$.

Philippine Statistics Authority [PSA]., 2016. Official poverty statistics of the Philippines: full year 2015. Quezon City, PH: Philippine Statistics Authority.

Philippine Statistics Authority [PSA]., 2016. Selected Statistics on Philippine Agriculture 2016. 60 pp.

Philippine Statistics Authority [PSA]. Administrative boundaries of the Philippines.

Republic Act 9729 [RA 9729]., 2009. An act mainstreaming climate change into government policy formulations, establishing the framework strategy and program on climate change, creating for this purpose the climate change commission, and for other purposes.

River Basin Control Office [DENR-RBCO]., 2007. Integrated river basin management and development master plan (main report): a national plan on sustainable and ecosystem management and development of the Philippine river basins. Quezon City, PH: DENR.

Roy, D. C., \& Blaschke, T., 2015. Spatial vulnerability assessment of floods in the coastal regions of Bangladesh. Geomatics, Natural Hazards and Risk, 6(1), 21-44. doi: 10.1080/19475705.2013.816785

Saaty, T. L., 1980. The Analytic Hierarchy Process. New York: McGraw-Hill.

Salmivaara, A., 2015. Spatial vulnerability assessments for water resources management (Doctoral dissertation). Retrieved 
from Aalto University, http://urn.fi/URN:ISBN:978-952-606283-9

Sehgal, V. K., \& Dhakar, R., 2016. Geospatial approach for assessment of biophysical vulnerability to agricultural drought and its intra-seasonal variations. Environmental Monitoring and Assessment, 188(3), 197. doi:10.1007/s10661-016-5187-5

Toda, L., Orduña, J. R., Lasco, R., Santos, C. T., 2016. Assessing social vulnerability to climate-related hazards among Haiyan-affected areas in the Philippines. Climate, Disaster and Development Journal, 1(1), 39-53.

Turner, B. L., Kasperson, R. E., Matson, P. A., McCarthy, J. J., Corell, R. W., Christensen, L., ... Schiller, A., 2003. A framework for vulnerability analysis in sustainability science. Proceedings of the National Academy of Sciences 100(14), 8074-8079. http://doi.org/10.1073/pnas.1231335100

University of the Philippines Training Center for Applied Geodesy and Photogrammetry [UP-TCAGP]., 2015. DREAM Flood Forecasting and Flood Hazard Mapping for Panay River Basin. Disaster Risk Exposure and Assessment for Mitigation (DREAM), DOST Grants-in-Aid Program, 69 pp. 